\title{
ORIGINAL
}

\section{Serum markers of brain injury can predict good neurological outcome after out-of-hospital cardiac arrest}

\author{
Marion Moseby-Knappe ${ }^{1 *}$ (D), Niklas Mattsson-Carlgren 1,2,3, Pascal Stammet ${ }^{4}$, Sofia Backman ${ }^{5}$, Kaj Blennow ${ }^{6,7}$, \\ Josef Dankiewicz ${ }^{8}$, Hans Friberg ${ }^{9}$, Christian Hassager ${ }^{10,11}$, Janneke Horn², Jesper Kjaergaard ${ }^{13}$, Gisela Lilja', \\ Christian Rylander ${ }^{14}$, Susann Ullén ${ }^{15}$, Johan Undén ${ }^{16,17}$, Erik Westhall ${ }^{5}$, Matt P. Wise ${ }^{18}$, Henrik Zetterberg 6,7,19,20,21, \\ Niklas Nielsen ${ }^{22}$ and Tobias Cronberg ${ }^{1}$
}

(c) 2021 The Author(s)

\begin{abstract}
Purpose: The majority of unconscious patients after cardiac arrest (CA) do not fulfill guideline criteria for a likely poor outcome, their prognosis is considered "indeterminate". We compared brain injury markers in blood for prediction of good outcome and for identifying false positive predictions of poor outcome as recommended by guidelines.

Methods: Retrospective analysis of prospectively collected serum samples at 24, 48 and $72 \mathrm{~h}$ post arrest within the Target Temperature Management after out-of-hospital cardiac arrest (TTM)-trial. Clinically available markers neuronspecific enolase (NSE) and S100B, and novel markers neurofilament light chain (NFL), total tau, ubiquitin carboxy-terminal hydrolase L1 (UCH-L1) and glial fibrillary acidic protein (GFAP) were analysed. Normal levels with a priori cutoffs specified by reference laboratories or defined from literature were used to predict good outcome (no to moderate disability, Cerebral Performance Category scale 1-2) at 6 months.
\end{abstract}

Results: Seven hundred and seventeen patients were included. Normal NFL, tau and GFAP had the highest sensitivities (97.2-98\% of poor outcome patients had abnormal serum levels) and NPV (normal levels predicted good outcome in $87-95 \%$ of patients). Normal S100B and NSE predicted good outcome with NPV 76-82.2\%. Normal NSE correctly identified 67/190 (35.3\%) patients with good outcome among those classified as "indeterminate outcome" by guidelines. Five patients with single pathological prognostic findings despite normal biomarkers had good outcome.

Conclusion: Low levels of brain injury markers in blood are associated with good neurological outcome after CA. Incorporating biomarkers into neuroprognostication may help prevent premature withdrawal of life-sustaining therapy.

Keywords: Blood biomarkers, Good neurological outcome, Cardiac arrest, Neurofilament light, Prognostication, ERC/ ESICM guidelines

\footnotetext{
*Correspondence: marion.moseby knappe@med.lu.se

${ }^{1}$ Department of Clinical Sciences Lund, Neurology, Skåne University Hospital, Lund University, Getingevägen 4, 22241 Lund, Sweden

Full author information is available at the end of the article
}

\section{实 Springer}




\section{Introduction}

Prediction of neurological outcome after cardiac arrest (CA) is mainly focused on identifying patients with extensive brain injury and a poor prognosis as recommended by guidelines [1-3]. The European Resuscitation Council (ERC) and European Society of Intensive Care Medicine (ESICM) algorithm for post-resuscitation care has recently been adjusted to increase prognostic accuracy [4]. Nonetheless, evaluations of the previous guideline algorithm suggest that a large proportion of patients will remain with indeterminate outcome after prognostication [5-7]. Furthermore, studies using propensity matched controls indicate that unconscious patients with potentially good outcome may be at risk of dying as a result of early withdrawal of life-sustaining therapy (WLST) for neurological reasons $[8,9]$. Therefore, early reliable tools are required to identify patients with limited brain injury.

Several indicators of good outcome exist; an early recovery of a normal voltage, continuous and reactive EEG-background within 12-24 h post arrest, a normal MRI scan or a Glasgow Coma Scale motor score $\geq 3$ have been reported to predict good outcome in $53-100 \%$ of patients [10-16]. The presence of brain stem reflexes, somatosensory-evoked cortical potentials or a normal computed tomography is less predictive of a good prognosis $[5,13,14,17,18]$. Blood biomarkers of brain injury are quantifiable and objective, and low blood levels may help identify patients with little or no brain injury to optimize allocation of resources and avoid pessimistic predictions in patients still affected by potent confounders such as remaining sedation. Furthermore, knowledge that a reasonable chance of recovery exist would be reassuring for the patient's family.

There is no standard for reporting indicators of mild or no brain injury [4], but two points are particularly relevant; first, that an abnormal test correctly identifies the majority of poor outcome patients, and second, that a normal test result is highly predictive of a good outcome.

We have previously published results on brain injury markers for prediction of poor neurological outcome using serum samples collected between 24 and $72 \mathrm{~h}$ post arrest within the biobank substudy of the Target Temperature Management after out-of-hospital cardiac arrest (TTM)-trial [19-25].

The aim of the current study was to examine whether normal levels of brain injury markers predict good neurological outcome after CA. We focused on neuronspecific enolase (NSE), the only marker recommended by guidelines [4], and on neurofilament light chain protein (NFL), a neuroaxonal marker which has previously demonstrated high prognostic accuracies [22, 26, 27]. In

\section{Take-home message}

In a large prospective international trial, both established and novel serum markers of brain injury predicted good neurological outcome as early as 24 hours after cardiac arrest. Normal levels of brain injury markers can be used to identify patients without severe brain injury where continued intensive care treatment could be life-saving.

addition, we report results for the neuroaxonal marker total tau, the neuronal cell body marker ubiquitin carboxy-terminal hydrolase L1 (UCH-L1) and the astrocytic markers S100B and glial fibrillary acidic protein (GFAP). We investigated if these markers could identify patients with an ultimate good outcome among those classified as with "indeterminate outcome" according to the ERC/ ESICM 2021 algorithm [4]. We also examined whether normal levels of brain injury markers could help identify patients with good oucome despite other pathological prognostic findings.

\section{Methods}

This was a retrospective analysis of prospectively collected serum samples within the TTM-trial, an international multicenter trial randomising 950 adult out-of-hospital cardiac arrest patients with a presumed cardiac cause of arrest to targeted temperature management at either $33{ }^{\circ} \mathrm{C}$ or $36{ }^{\circ} \mathrm{C}[19,28]$. The trial found no difference between the two allocation groups in survival or neurological outcome after 6 months [19]. A majority of sites participated in the biobank substudy collecting serum samples at 24, 48 and $72 \mathrm{~h}$ post arrest [20]. Results for poor outcome prediction have been published [20-24]. The number of missing data from patients alive at each time point was low, and we found no systematic differences between patients with missing and available biomarker data [20-24].

NSE and S100B concentrations were measured with an electrochemiluminescence immunoassay kit on a Cobas e601 (Roche Diagnostics, Rotkreuz, Switzerland) $[20,21]$. For NSE, all samples with a positive haemolysis index $\geq 500 \mathrm{mg} / \mathrm{L}$ were discarded [20]. NFL and tau concentrations were measured on the Simoa HD-1 Analyzer (Quanterix, Billerica, MA) with a Homebrew kit or Human Total Tau kit, respectively [22, 24]. UCH-L1 and GFAP were analysed with a chemiluminescent enzymelinked immunosorbent assay (Banyan Biomarkers, San Diego, CA) [23].

Normal values were defined using a priori cutoffs based on our laboratories reference standards or from literature; $\mathrm{NSE}<17 \mathrm{ng} / \mathrm{mL}$ [20]; S100B $<0.105 \mu \mathrm{g} / \mathrm{L}$ [21]; $\mathrm{NFL}<55 \mathrm{pg} / \mathrm{mL}$, similar to the highest normal values described by Hviid et al.[29]; UCH-L1 $<327 \mathrm{pg} / \mathrm{mL}$ and GFAP $<22 \mathrm{pg} / \mathrm{mL}$ guided by the ALERT-TBI-trial for 
preventing unnecessary radiation in patients after mild traumatic brain injury [30]. Total tau $\leq 1.55 \mathrm{pg} / \mathrm{mL}$ was based on a control group by Mattsson et al., since tau serum concentrations are approximately $60 \%$ of plasma concentrations [31,32].

Original EEGs were evaluated centrally after trial completion by investigators blinded to clinical information, neuroimaging and SSEP were evaluated at the patients local hospital as published [5, 17, 18, 33-37]. Neurological outcome was dichotomized according the Cerebral Performance Category Scale as good (CPC 1-2, no to moderate cerebral disability) or poor (CPC $3-5$, severe cerebral disability, vegetative state or death) at 6 months. Written informed consent was waived or obtained from all patients or proxies according to national legislation [19].

\section{Statistical analysis}

Baseline data are presented in numbers (percentages) or median (interquartile range). Prognostic accuracies were calculated for normal concentrations and $2 \times$ normal concentrations, derived as described in methods. Serum levels were considered "true positive" if elevated above normal in a poor outcome patient and "true negative" if within normal range in a good outcome patient [38]. This is in accordance with STARD guidelines for reporting of diagnostic and prognostic accuracies, where "positive" is defined as "disease confirmed" (in this case poor outcome) and "negative" as "disease excluded" [39]. Sensitivity, specificity, NPV (normal serum levels and good outcome) and PPV (abnormal serum levels and poor outcome) are presented with $95 \%$ confidence intervals calculated with Wilson's method [38]. Overall prognostic accuracies were calculated by receiver operating characteristics (ROC) curves. Cutoffs at a set high sensitivity and a set high specificity were calculated with a bootstrap procedure.

We evaluated whether normal levels of biomarkers could help identify good outcome patients classified as with "indeterminate outcome" according to the ERC/ ESICM algorithm [4]. Patients who died $<72 \mathrm{~h}$ after CA, patients awake and obeying commands $<72 \mathrm{~h}$ and those fulfilling guideline criteria of "poor outcome likely" were excluded, to simulate the clinical setting of neuroprognostication $\geq 72 \mathrm{~h}$ post arrest.

We describe the overall concordance between normal levels of biomarkers and pathological prognostic examinations, and examine whether brain injury markers could help identify false positive patients with good oucome despite pathological findings.

Statistical analyses were performed with $\mathrm{R}$, version 3.5.1 (The R Foundation for Statistical Computing) [40].

\section{Results}

Seven hundred and seventeen patients had results of at least one biomarker (NSE, S100B, NFL, tau, UCH-L1 and GFAP), 683 patients had all six biomarkers analysed on at least 1 time point and missing data was low (eFig. 1A-B, Table 1).

\section{Elevated serum concentrations above normal levels}

Prognostic accuracies of normal biomarker levels can be seen in Table 2. NFL levels were within normal range in $48.2-65 \%$ of patients with good outcome (specificity) and elevated above normal levels in $95.4-97.5 \%$ of poor outcome patients (sensitivity). Normal NFL levels correctly predicted a good outcome in $93.3-95 \%$ of patients (NPV) but $27.5-36.6 \%$ of patients with NFL levels above normal also achieved a good outcome (1-PPV). GFAP had similarly high sensitivity and NPV as NFL, but NFL correctly identified a larger absolute number of patients with good outcome (TN) compared to GFAP.

If serum levels were within normal range at all time points between 24 and $72 \mathrm{~h}$, NPV increased slightly for all markers except tau, compared to single time points alone. For NSE, $82.2 \%$ of patients with normal serum levels $(<17 \mathrm{ng} / \mathrm{mL})$ at all timepoints had good neurological outcome (NPV). In comparison, if tau, GFAP or NFL was within normal range at all timepoints, outcome was good in $87-95 \%$. Of the remaining markers, UCH-L1 performed similarly to NSE, and S100B had the lowest NPV. By doubling normal levels, a larger

Table 1 Patient characteristics

\begin{tabular}{lll}
\hline & $\begin{array}{l}\text { At least 1 sample } \\
\text { of any marker } \\
\mathbf{N = 7 1 7}\end{array}$ & $\begin{array}{l}\text { All } 6 \text { mark- } \\
\text { ers available } \\
\mathbf{N}=683\end{array}$ \\
\hline Age & $65(56-73)$ & $65(56-73)$ \\
Male & $580(80.9)$ & $552(80.8)$ \\
Minutes to ROSC & $25(17-39)$ & $25(16-39)$ \\
Initial rhythm shockable & $558(77.8)$ & $537(78.6)$ \\
TTM $33^{\circ} \mathrm{C}$ & $359(50.1)$ & $343(50.2)$ \\
CPC at 6 months & & $304(44.5)$ \\
\hline 1 & $313(44)$ & $43(6.3)$ \\
\hline 2 & $44(6.1)$ & $27(4)$ \\
\hline 3 & $28(3.9)$ & $8(1.1)$ \\
\hline 4 & $8(1.1)$ & $301(44.1)$ \\
\hline 5 & $324(45.2)$ & \\
\hline
\end{tabular}

When calculating prognostic accuracies for normal values of the ERC/ESICM algorithm, all available data for any marker available on 24, 48 and/or $72 \mathrm{~h}$ post-arrest was included ( $N=717$ patients). Patients with results from all six biomarkers (NSE, S100B, NFL, tau, UCH-L1 and GFAP) on $\geq 1$ time point were included when directly comparing prognostic accuracies between markers $(N=683)$. Results are presented as median (interquartile range) or numbers (percentages). ROSC; return of spontaneous circulation, TTM $33^{\circ} \mathrm{C}$; randomized to targeted temperature management $33^{\circ} \mathrm{C}, \mathrm{CPC} ;$ Cerebral Performance Category Scale at 6 months post-arrest 
Table 2 Prognostic accuracies for normal range serum levels

\begin{tabular}{|c|c|c|c|c|c|c|c|c|c|}
\hline Biomarker/time & Sensitivity $(95 \% \mathrm{CI})$ & Specificity (95\% CI) & NPV & PPV & TN & FN & TP & FP & $\mathbf{N}$ \\
\hline NSE $24 \mathrm{~h}$ & $85(80.7-88.5)$ & $46.4(41.1-51.8)$ & $76.1(69.8-81.5)$ & $60.6(56-65)$ & 153 & 48 & 272 & 177 & 650 \\
\hline NSE $48 \mathrm{~h}$ & 83.6 (78.9-87.4) & $57.5(52.3-63)$ & 79.5 (73.9-84.2) & $64.2(59.3-68.9)$ & 186 & 48 & 244 & 136 & 614 \\
\hline NSE $72 \mathrm{~h}$ & $80.4(75.2-84.7)$ & 74.9 (69.8-79.4) & $81.6(77.6-85.7)$ & $73.4(68.1-78.2)$ & 230 & 52 & 213 & 77 & 572 \\
\hline NSE any time point & $91.7(88.3-94.2)$ & $37.1(32.2-42.3)$ & $82.2(75.4-87.4)$ & $58.7(54.4-62.8)$ & 129 & 28 & 311 & 219 & 687 \\
\hline S100B $24 \mathrm{~h}$ & 74.1 (69-78.6) & $69.3(64.1-74)$ & $73.3(68.1-77.9)$ & 70.1 (65-74.8) & 228 & 83 & 237 & 101 & 649 \\
\hline S100B $48 \mathrm{~h}$ & $71.9(66.5-76.8)$ & $73.2(68.2-77.8)$ & 70.1 (69.3-78.9) & $74.4(65.3-75.6)$ & 238 & 82 & 210 & 87 & 617 \\
\hline S100B $72 \mathrm{~h}$ & $63.4(57.4-69)$ & $81.1(76.5-85.1)$ & $74(67.5-76.8)$ & 72.4 (67.9-79.3) & 254 & 97 & 168 & 59 & 578 \\
\hline S100B any time point & 80.5 (76-84.4) & $59.9(54.7-64.9)$ & $76(70.6-80.7)$ & $66.1(61.4-70.5)$ & 209 & 66 & 273 & 140 & 688 \\
\hline NFL 24 h & $95.4(92.5-97.1)$ & $65(59.8-69.8)$ & $93.4(89.6-95.9)$ & $72.5(68.2-76.5)$ & 228 & 16 & 325 & 123 & 692 \\
\hline NFL $48 \mathrm{~h}$ & $96(93.2-97.6)$ & $53.7(48.4-59)$ & 93.3 (88.9-96) & $66.4(62-70.5)$ & 181 & 13 & 308 & 156 & 658 \\
\hline NFL $72 \mathrm{~h}$ & $96.5(93.7-98.1)$ & $50.8(45.3-56.2)$ & $94.3(89.8-96.9)$ & $63.4(58.7-67.8)$ & 164 & 10 & 275 & 159 & 608 \\
\hline NFL any time point & 97.5 (95.3-98.7) & $48.2(43-53.4)$ & 95 (90.8-97.4) & $65.4(61.3-69.3)$ & 172 & 9 & 350 & 185 & 716 \\
\hline GFAP $24 \mathrm{~h}$ & $96.8(94.4-98.2)$ & $40.8(35.7-46)$ & $92.3(87.5-95.9)$ & $61.8(57.7-65.8)$ & 141 & 11 & 332 & 205 & 689 \\
\hline GFAP $48 \mathrm{~h}$ & $97.2(94.7-98.5)$ & $35.3(30.4-40.6)$ & $92.9(87.1-96.2)$ & $59(54.8-63.1)$ & 118 & 9 & 311 & 216 & 654 \\
\hline GFAP $72 \mathrm{~h}$ & 95.1 (91.9-97) & $44.4(39.1-50)$ & $90.9(85.3-94.5)$ & $60.7(56.1-65.1)$ & 140 & 14 & 270 & 175 & 599 \\
\hline GFAP any time point & $98(96-99)$ & $31(26.4-36)$ & $94(88.2-97.1)$ & $58.9(54.9-62.8)$ & 110 & 7 & 351 & 245 & 713 \\
\hline Tau $24 \mathrm{~h}$ & $93.6(90.4-95.7)$ & $28.3(23.9-33.2)$ & $82(74.2-87.8)$ & $55.8(51.7-59.8)$ & 100 & 22 & 319 & 253 & 694 \\
\hline Tau $48 \mathrm{~h}$ & $95(92.1-96.9)$ & $41.3(36.2-46.6)$ & 89.7 (84-93.6) & $60.6(56.3-64.8)$ & 140 & 16 & 306 & 199 & 661 \\
\hline Tau 72 h & $93(89.5-95.4)$ & $51.7(46.3-57.1)$ & 89.4 (84.1-93) & $62.9(58.2-67.4)$ & 168 & 20 & 266 & 157 & 611 \\
\hline Tau any time point & $97.2(95-98.5)$ & $18.8(15.1-23.1)$ & 87 (77.7-92.8) & $54.6(50.7-58.4)$ & 67 & 10 & 349 & 290 & 716 \\
\hline UCH-L1 $24 \mathrm{~h}$ & $85.2(81.1-88.6)$ & $63.8(58.6-68.7)$ & $81.3(76.3-85.5)$ & $70(65.5-74.2)$ & 222 & 51 & 294 & 126 & 693 \\
\hline UCH-L1 $48 \mathrm{~h}$ & $81.7(77.2-85.6)$ & $73.8(68.9-78.2)$ & $81(76.2-85-0)$ & $74.8(70-79)$ & 251 & 59 & 264 & 89 & 663 \\
\hline UCH-L1 $72 \mathrm{~h}$ & $70.3(64.8-75.3)$ & $88.1(84.1-91.2)$ & $77.4(72.9-81.4)$ & $83.6(78.4-87.8)$ & 288 & 84 & 199 & 39 & 610 \\
\hline UCH-L1 any time point & $89.4(85.8-92.2)$ & $53.7(48.5-58.8)$ & $83.4(78-87.7)$ & $66(61.7-70)$ & 191 & 38 & 320 & 165 & 714 \\
\hline
\end{tabular}

Prognostic accuracies with $95 \%$ confidence intervals for normal values as defined in method at $24-72 \mathrm{~h}$ after cardiac arrest using all data available. Neurological outcome was dichotomized into good (CPC 1-2) and poor (CPC 3-5) at 6 months post-arrest. Prognostic accuracies on "any time point" indicates that serum levels were elevated above expected normal values on at least one time point. A sensitivity of $95.4 \%$ for NFL at $24 \mathrm{~h}$ indicates that $95.4 \%$ of poor outcome patients had abnormal serum NFL. The corresponding $65 \%$ specificity indicates that $65 \%$ of good outcome patients had NFL levels within normal range. A negative predictive value (NPV) of $93.4 \%$ indicates that if serum neurofilament light (NFL) at $24 \mathrm{~h}$ was within normal range, outcome was good in $93.4 \%$ of patients. A positive predictive value (PPV) of $72.5 \%$ indicates that if NFL was abnormal at $24 \mathrm{~h}$ post-arrest, outcome was poor in $72.5 \%$

NSE neuron-specific enolase, GFAP glial fibrillary acidic protein total tau, UCH-L1 ubiquitin carboxy hydrolase L1, TN true negative (low biomarker levels in good outcome patients), FN false negative (low biomarker levels in poor outcome patients), TP true positive (high biomarker levels in poor outcome patients), FP false positive (high biomarker levels in good outcome patients), $N$ number of samples

number of good outcome patients were correctly identified (specificity), but an increasing number of poor outcome patients also had serum levels below cut-off, decreasing sensitivity and NPV (eTable 1). Patients with normal levels of brain injury markers more often had a non-neurological presumed cause-of-death compared to patients with abnormal levels (eTable 2).

\section{Corresponding cutoff values at high sensitivities and specificities}

ROC curves and tables with overall prognostic performance of all biomarkers, corresponding cutoff values at set high sensitivity and a set high specificity are displayed in eFig. 2, eTables 3 and 4.

\section{"Indeterminate outcome" according to the ERC/ESICM algorithm}

We next evaluated whether patients with "indeterminate outcome" according to the ERC/ESICM 2021 algorithm could be further classified by normal levels of NSE (Fig. 1). The algorithm correctly identified 82 patients with a final poor outcome (0\% FPR) and another 181 were awake on day 3. Among the remaining 382 patients with "indeterminate outcome", 85 had NSE within normal range, the majority (78.8\%) of whom had a good final outcome. Conversely, "indeterminate" patients with abnormal NSE had good outcome in $43.5 \%$.

Normal NFL, GFAP or tau had higher sensitivity and NPV than NSE in "indeterminate" patients (Table 3). NFL had significantly higher overall prognostic accuracy than all other biomarkers in "indeterminate" patients, and the 


\section{ERC/ESICM guideline algorithm and "indeterminate" outcome}

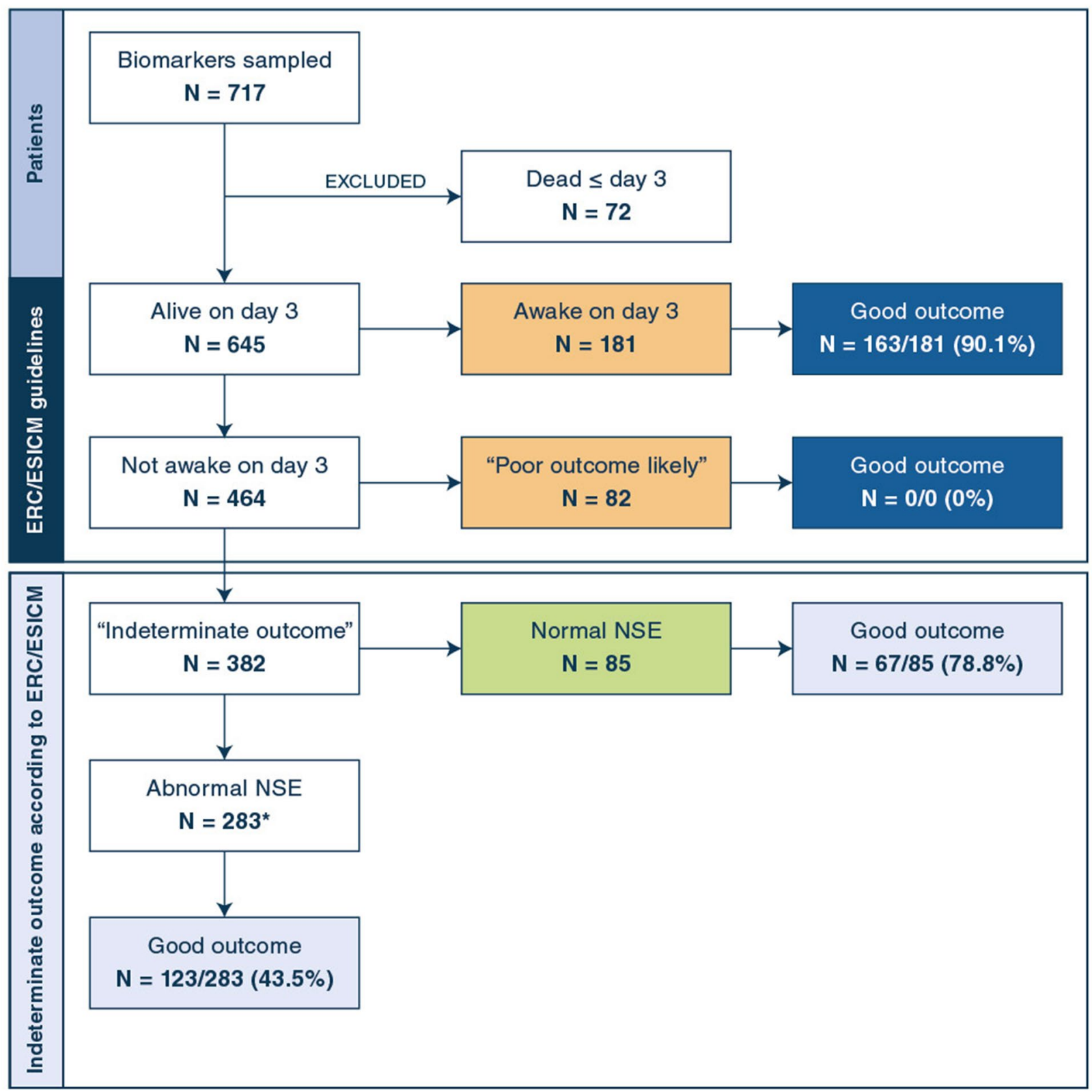

Fig. 1 ERC/ESICM guideline algorithm and "indeterminate outcome". Only patients with at least one brain injury marker sampled after 24,48 or $72 \mathrm{~h}$ and alive $>72 \mathrm{~h}$ post-arrest were included. "Awake on day 3" refers to patients awake and obeying commands [Glasgow Coma Scale Motor Score $(G C S-M)=6]$ at 48-72 h post-arrest. Poor neurological outcome was defined as Cerebral Performance Category Scale 3-5 at 6 months follow-up. "Poor outcome likely" refers to patients fulfilling 2021 ERC/ESICM criteria [4]; GCS-M $\leq 3>72 \leq 96$ h post-arrest AND $\geq 2$ pathological findings; (bilaterally absent corneal and pupillary reflexes, bilaterally absent N20 potentials on somatosensory-evoked potentials, diffuse and extensive hypoxic injury on CT or MRI, highly malignant EEG patterns, early generalized status myoclonus, NSE $\geq 60 \mathrm{ng} / \mathrm{mL}$ at 48 or $72 \mathrm{~h}$ post-arrest). "Indeterminate outcome" refers to patients alive and not awake on day 3 who do not fulfill ERC/ESICM criteria of poor outcome likely. ${ }^{*}$ Missing NSE in N=14 patients

association remained significant after adjusting for targeted temperature management (eTable 5).
Pathological prognostic findings in patients with normal biomarker levels

We investigated whether patients with brain injury markers within normal range had indicators of a "poor 
Table 3 Prognostic accuracies in patients with indeterminate outcome according to the ERC/ESICM algorithm

\begin{tabular}{|c|c|c|c|c|c|c|c|c|c|}
\hline & Sensitivity & Specificity & NPV & PPV & TN & FN & TP & FP & $N$ \\
\hline NSE $17 \mathrm{ng} / \mathrm{mL}$ & $89.9(84.6-93.5)$ & $35.3(28.8-42.3)$ & 78.8 (69-86.2) & $56.5(50.7-62.2)$ & 67 & 18 & 160 & 123 & 368 \\
\hline S100B $0.105 \mu \mathrm{g} / \mathrm{L}$ & $72.6(65.7-78.6)$ & $55.5(48.4-62.4)$ & $68.4(60.7-75.2)$ & $60.5(53.8-66.8)$ & 106 & 49 & 130 & 85 & 370 \\
\hline $\mathrm{NFL} 55 \mathrm{pg} / \mathrm{mL}$ & $96.3(92.5-98.2)$ & $38.7(32.1-45.7)$ & 91.5 (83.4-95.8) & $60.3(54.7-65.7)$ & 75 & 7 & 181 & 119 & 382 \\
\hline GFAP $22 \mathrm{pg} / \mathrm{mL}$ & 97.3 (93.9-98.9) & $26.4(20.7-33.1)$ & $91.1(80.7-96.1)$ & $56.3(50.9-61.6)$ & 51 & 5 & 183 & 142 & 381 \\
\hline Tau 1.55 pg/mL & $95.7(91.8-97.8)$ & $19.6(14.6-25.7)$ & $82.6(69.3-90.9)$ & $53.6(48.2-58.8)$ & 38 & 8 & 180 & 156 & 382 \\
\hline UCH-L1 $327 \mathrm{pg} / \mathrm{mL}$ & 85 (79.2-89.4) & $47.7(40.7-54.7)$ & 76.7 (68.4-83.3) & $61.1(55.1-66.9)$ & 92 & 28 & 159 & 101 & 380 \\
\hline
\end{tabular}

Prognostic accuracies with $95 \%$ confidence intervals in patients classified as with indeterminate outcome according to the ERC/ESICM algorithm as displayed in Fig. 1 ( $N=382$ patients). Normal values were defined as described in methods and classified as pathological if elevated above cut-off at least once on any timepoint. Neurological outcome was dichotomized into good (Cerebral Performance Categories Scale 1-2) and poor (Cerebral Performance Category Scale 3-5) at 6 months post-arrest

$T N$ true negative (low biomarker levels in good outcome patients), FN false negative (low biomarker levels in poor outcome patients), TP true positive (high biomarker levels in poor outcome patients), FP false positive (high biomarker levels in good outcome patients), NPV negative predictive value (amount of good outcome patients with normal serum concentrations), PPV positive predictive value (amount of poor outcome patients with abnormal serum concentrations), $N=$ number of samples

outcome likely" derived by other recommended methods [4]. In total, sixteen patients had indicators of poor outcome and normal levels of at least one of the six biomarkers (Table 4). Five patients who eventually had a good outcome had single pathological findings; three had normal NFL levels, one with bilaterally absent N20 on SSEP, a second with highly malignant EEG and a third with early-status myoclonus. Two additional patients had early generalised oedema on head computed tomography and normal NSE, GFAP or UCH-L1 (eTable 6).

Eleven patients with poor outcome had $\geq 1$ pathological finding despite normal serum levels of at least one biomarker (eTable 7). In particular, NSE levels were normal or mildly elevated in a few patients with severely elevated NFL, tau and GFAP. Nine patients had normal S100B, yet levels of other markers were severely elevated $\geq 10 \times$ above normal. Five poor outcome patients with normal levels of at least one biomarker would have fulfilled criteria of "poor outcome likely", three of which died prior to formal prognostication.

\section{Discussion}

In this multicenter international study using prospectively collected serum samples, we found that all examined markers of brain injury had the potential to identify patients with good neurological outcome from $24 \mathrm{~h}$ after CA. Furthermore, normal levels of the routine marker NSE correctly identified one-third of good outcome patients classified as with "indeterminate outcome" according to the ERC/ESICM algorithm. We found that normal serum levels of biomarkers indicating limited brain injury could help identify patients at risk for selffulfilling prophecies when results from other examinations are disconcordant.

Previously, we explored these established and novel brain injury markers for prediction of poor outcome after CA [20-24]. There should also be a great clinical utility for early quantitative and objective predictors of good outcome. While ninety percent of our patients who woke up within $72 \mathrm{~h}$ post arrest had good neurological outcome and all patients fulfilling ERC/ESICM criteria of "poor outcome likely" had poor outcome, a large number of patients remain unconscious but do not fulfill criteria of "poor outcome likely". There is currently insufficient knowledge on how to identify the patients with potential for recovery among these with "indeterminate outcome" which typically require prolonged time for observation until awakening, potentially due to slow metabolism of sedatives or extensive treatment of status epilepticus [37, 41].

In this study, we provide evidence for the use of biomarkers in this context and we also demonstrate that normal levels of brain injury markers could help identify patients at risk for self-fulfilling prophecies due to single false positive prognostic findings from other established methods for neuroprognostication.

We found that normal levels of any brain injury marker below a priori cutoffs predicted good outcome with reasonable prognostic accuracy from $24 \mathrm{~h}$ post arrest and that doubled normal levels substantially increased the amount of good outcome patients correctly identified. This is of immediate clinical importance, since NSE and S100B are already routinely in use. Serum NSE $\leq 17 \mathrm{ng} /$ $\mathrm{mL}$ correctly predicted good outcome in $76.1-82.2 \%$ of our patients. Our results are similar to those reported by Streitberger et al, where NSE $\leq 17 \mathrm{ng} / \mathrm{mL}$ excluded vegetative state or death (CPC 4-5) in 92\% of patients [42]. Rossetti et al. found that NSE predicted good neurological outcome in $63.1 \%$ of patients with a cutoff $<75 \mathrm{ng} /$ $\mathrm{mL}$, which is well above our clinically established values for poor outcome prediction [5, 13]. S100B, often used as a prognostic marker after traumatic brain injury, 


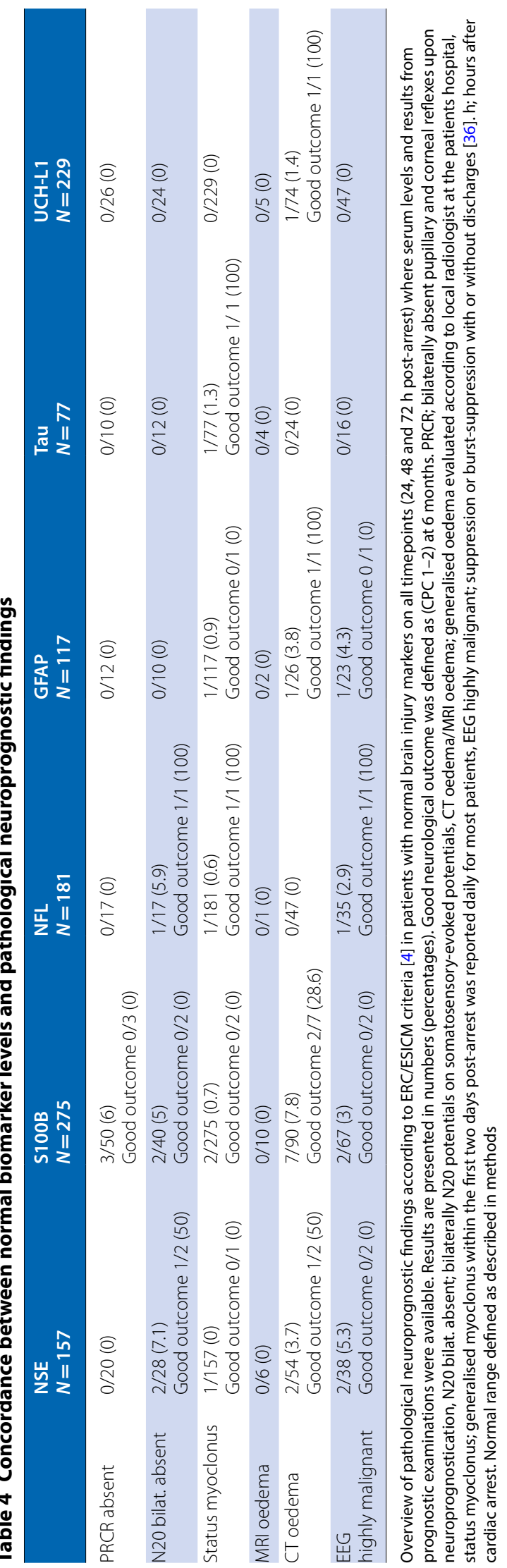


was the least convincing predictor of good outcome in our cohort, yet correctly predicted good outcome in $70.1-76 \%$.

Overall, we found that $94-95 \%$ of patients with normal levels of the neuroaxonal marker NFL or the astrocytic GFAP had good outcome after 6 months. NFL correctly predicted good outcome in a larger number of patients than GFAP. Our results are in accordance with the higher overall prognostic accuracy for NFL reported in previous studies [22, 23, 26]. Elevated GFAP levels may indicate both astrocytic injury and an upregulation of glial activity $[43,44]$. Absence of glial stress indicated by normal GFAP may thus be relevant to predict the absence of subsequent brain injury. In contrast, tau, is present in unmyelinated axons of neurons, but also in astrocytes and oligodendrocytes, which may explain why low serum concentrations indicate little or no injury (or astrocytic upregulation) [45]. All three markers are currently studied as prognostic markers within various neurological conditions and may soon become widely available [30, 31, $46,47]$.

We asked ourselves whether normal levels of brain injury markers would be useful in a clinical setting to classify patients who remain unconscious at $72 \mathrm{~h}$ post arrest. For this analysis, we excluded patients who would not have undergone neurological prognostication due to awakening and those fulfilling criteria for poor outcome. We only included the remaining patients with "indeterminate outcome" where a "wait-and-see-approach" is recommended [4]. We found that normal levels of NSE could be useful to identify good outcome patients, although NFL and GFAP demonstrated the highest predictive values for good outcome (91\%). Our results may be especially relevant where early WLST is commonly performed in absence of clinical improvement, or when triaging intensive care patients when resources are scarce.

Guidelines recommend caution that prognostic examinations are concordant in their prediction (for example signs of severe brain injury) [4]. We found, that pathological prognostic findings were uncommon in patients with normal concentrations of brain injury markers. Five patients with normal NFL, tau or UCH-L1 had good outcome despite single pathological findings. These results indicate that normal levels may indeed be helpful to identify false positive predictions of poor outcome. The question arises why eleven poor outcome patients had several pathological findings but normal levels of at least one biomarker. We found that patients with normal NSE could have moderately to severely elevated levels of other markers, such as NFL, GFAP and tau, indicating their superiority for good outcome prediction. Additionally, the majority of patients with poor outcome despite low levels of at least one biomarker had a non-cerebral causeof-death, demonstrating that brain injury markers are only predictive of neurological futility.

Blood biomarkers are quantifiable and objective, but sources of error exist, such as elevated concentrations of brain injury markers released from extracerebral tissue or as a result of neuronal injury caused by sedation [48-50]. Targeted temperature management did not influence the correlation between brain injury markers and neurological outcome. We stress that serum levels above normal range do not automatically indicate that neurological outcome will be poor. On the contrary, NFL levels were elevated in approximately one-third of good outcome patients. Therefore, the cutoffs for normal range, in contrast to cutoffs for poor outcome, should not be used to terminate care, but rather for emphasizing continued care.

\section{Strengths and limitations}

The main strengths of this study include the prospective and multicenter design, a large sample size, a conservative protocol for neurological prognostication, strict criteria for WLST, face-to-face evaluation of outcome and a priori cutoffs for brain injury markers. Analyses were performed after trial completion by laboratory technicians blinded to clinical information. Biomarker levels were not available for clinical decision-making. Nonetheless, we cannot exclude that an even more conservative approach to WLST could have led to additional good outcomes. Our results apply to a group of patients resuscitated from a presumed cardiac cause of arrest. Although hypoxic-ischemic brain injury occurs in all aetilogies of CA, biomarker levels might be influenced by sepsis, trauma or other factors triggering the initial event. Additionally all patients in this report received temperature control to levels below $37{ }^{\circ} \mathrm{C}$ and protocolized sedation for at least $36 \mathrm{~h}$, mechanical cardiac support was uncommon. These factors could conceivably influence results.

We emphasize that the novel markers NFL, tau, UCH-L1 and GFAP are currently only available as research-grade tests. While clinical laboratories in Sweden, the Netherlands and France have validated the NFL assay for use in clinical laboratory practice, it is not yet available as a $24-7$ test. Additionally, GFAP and UCH-L1 have gained FDA approval for use as biomarkers of good outcome to avoid unnecessary computerised tomography scans following concussion, which bodes well for their future clinical use as outcome markers following CA [30, 51]. NSE and S100B, although diagnostically less robust, are currently available in many clinical chemistry laboratories [50]. Future research should aim to establish international calibration standards and defining normal values for all age groups. 


\section{Conclusion}

Low levels of brain injury markers in blood after CA are associated with good neurological outcome and absence of pathological prognostic findings. Use in clinical practice of currently available markers NSE and S100B may help prevent death through premature WLST. The biomarker NFL showed the highest predictive capacity and may become an important addition to current clinical tools in the near future.

\section{Supplementary Information}

The online version contains supplementary material available at https://doi. org/10.1007/s00134-021-06481-4.

\begin{abstract}
Author details
${ }^{1}$ Department of Clinical Sciences Lund, Neurology, Skåne University Hospital, Lund University, Getingevägen 4, 22241 Lund, Sweden. ${ }^{2}$ Clinical Memory Research Unit, Faculty of Medicine, Lund University, Lund, Sweden. ${ }^{3}$ Wallenberg Centre for Molecular Medicine, Lund University, Lund, Sweden. ${ }^{4}$ Medical and Health Department, National Fire and Rescue Corps, Luxembourg, Luxembourg. ${ }^{5}$ Department of Clinical Sciences Lund, Clinical Neurophysiology, Skåne University Hospital, Lund University, Lund, Sweden. ${ }^{6}$ Department of Psychiatry and Neurochemistry, The Sahlgrenska Academy, Institute of Neuroscience and Physiology, University of Gothenburg, Mölndal, Sweden. ${ }^{7}$ Clinical Neurochemistry Laboratory, Sahlgrenska University Hospital, Mölndal, Sweden. ${ }^{8}$ Department of Clinical Sciences Lund, Cardiology, Skåne University Hospital, Lund University, Lund, Sweden. ${ }^{9}$ Department of Clinical Sciences Lund, Anaesthesia and Intensive Care, Skåne University Hospital, Lund University, Malmö, Sweden. ${ }^{10}$ Department of Cardiology, Rigshospitalet, University of Copenhagen, Copenhagen, Denmark. ${ }^{11}$ Department of Clinical Medicine, University of Copenhagen, Copenhagen, Denmark. ${ }^{12}$ Department of Intensive Care, Amsterdam Neuroscience, Amsterdam UMC, Location Academic Medical Center, Amsterdam, The Netherlands. ${ }^{13}$ Department of Cardiology, Copenhagen University Hospital Rigshospitalet, Copenhagen, Denmark. ${ }^{14}$ Department of Anaesthesiology and Intensive Care Medicine, Sahlgrenska Academy, Institute of Clinical Sciences, University of Gothenburg, Gothenburg, Sweden.

${ }^{15}$ Clinical Studies Sweden-Forum South, Skane University Hospital, Lund, Sweden. ${ }^{16}$ Department of Clinical Sciences Malmö, Lund University, Malmö, Sweden. ${ }^{17}$ Department of Operation and Intensive Care, Lund University, Hallands Hospital Halmstad, Halland, Sweden. ${ }^{18}$ Adult Critical Care, University Hospital of Wales, Cardiff, UK. ${ }^{19}$ Department of Neurodegenerative Disease, UCL Institute of Neurology, London, UK. ${ }^{20}$ UK Dementia Research Institute at UCL, London, UK. ${ }^{21}$ Hong Kong Center for Neurodegenerative Diseases, Hong Kong, China. ${ }^{22}$ Department of Clinical Sciences Lund, Anaesthesia and Intensive Care, Helsingborg Hospital, Lund University, Lund, Sweden.
\end{abstract}

\section{Acknowledgements}

The authors would like to thank the TTM-trial investigators and the sponsors for their support. We thank the staff at the Clinical Neurochemistry Laboratory in Mölndal, Sweden, Banyan Biomarkers, San Diego, CA, the biochemistry laboratory of the Centre Hospitalier de Luxembourg and the Integrated BioBank of Luxembourg for analysis and storage of samples.

\section{Author contributions}

Concept and design: MMK, TC, NN, NMC, HZ, KB, PS, HF. Acquisition, analysis, or interpretation of data: all authors. Drafting the manuscript: MMK, TC. Critical revision of the manuscript for important intellectual content and approved the version to be published: all authors. Statistical analysis: MMK, TC, NMC, SU. Obtained funding: MMK, TC, NN, HZ, KB. Administrative, technical, or material support: the authors would like to thank the TTM-trial investigators and the sponsors for their support. We thank the staff at the Clinical Neurochemistry Laboratory in Mölndal, Sweden, Banyan Biomarkers, San Diego, CA, the biochemistry laboratory of the Centre Hospitalier de Luxembourg and the Integrated BioBank of Luxembourg for analysis and storage of samples. Supervision: TC, NMC, SU. Agree to be accountable for all aspects of the work in ensuring that questions related to the accuracy or integrity of any part of the work are appropriately investigated and resolved: all authors.

\section{Funding}

Open access funding provided by Lund University. Funding for the study was provided by the Swedish Research Council, Swedish Heart Lung Foundation, Arbetsmarknadens Försäkringsaktiebolag Insurance Foundation, the Skåne University Hospital Foundations, the Gyllenstierna-Krapperup Foundation, and governmental funding of clinical research within the Swedish National Health System, the County Council of Skåne; the Swedish Society of Medicine; the Koch Foundation; TrygFonden (Denmark); European Clinical Research Infrastructures Network; Thelma Zoega Foundation; Stig and Ragna Gorthon Foundation; Thure Carlsson Foundation; Hans-Gabriel and Alice TrolleWachtmeister Foundation for Medical Research; Lions Research fund Skåne; South Swedish Hospital Region Research Funds; the Swedish Brain Foundation; the Lundbeck Foundation; and the Torsten Söderberg foundation at the Royal Swedish Academy of Sciences. HZ is a Wallenberg Scholar. NMC is a Wallenberg Molecular Medicine Fellow.Role of the Funder/Sponsor: the funding organizations had no role in the design and conduct. of the study; collection, management, analysis, and interpretation of the data; preparation, review, or approval of the manuscript; and decision to submit the manuscript for publication.

\section{Declarations}

\section{Conflicts of interest}

MMK, NMC, PS, SB, JD, HF, CH, JH, GL, CR, SU, JH, EW, MW, NN and TC report no conflicts of interest. HZ has served at scientific advisory boards for Eisai, Denali, Roche Diagnostics, Wave, Samumed, Siemens Healthineers, Pinteon Therapeutics, Nervgen, AZTherapies and CogRx, has given lectures in symposia sponsored by Cellectricon, Fujirebio, Alzecure and Biogen, and is a co-founder of Brain Biomarker Solutions in Gothenburg AB (BBS), which is a part of the GU Ventures Incubator Program (outside submitted work). KB has served as a consultant, at advisory boards, or at data monitoring committees for Abcam, Axon, Biogen, JOMDD/Shimadzu. Julius Clinical, Lilly, MagQu, Novartis, Roche Diagnostics, and Siemens Healthineers, and is a co-founder of Brain Biomarker Solutions in Gothenburg AB (BBS), which is a part of the GU Ventures Incubator Program. JK reports funding from NovoNordisk foundation NNF17OC0028706, for work outside the present manuscript.

\section{Ethics approval}

The TTM-trial was approved by the Regional Ethical Review Board at Lund University, Sweden and by the appropriate research ethics committees in each participating country. The study was performed in accordance with the ethical standards as laid down in the 1964 Declaration of Helsinki and its later amendments.

\section{Open Access}

This article is licensed under a Creative Commons Attribution-NonCommercial 4.0 International License, which permits any non-commercial use, sharing, adaptation, distribution and reproduction in any medium or format, as long as you give appropriate credit to the original author(s) and the source, provide a link to the Creative Commons licence, and indicate if changes were made. The images or other third party material in this article are included in the article's Creative Commons licence, unless indicated otherwise in a credit line to the material. If material is not included in the article's Creative Commons licence and your intended use is not permitted by statutory regulation or exceeds the permitted use, you will need to obtain permission directly from the copyright holder. To view a copy of this licence, visit http://creativecommons.org/licen ses/by-nc/4.0/.

\section{Publisher's Note}

Springer Nature remains neutral with regard to jurisdictional claims in published maps and institutional affiliations.

Received: 11 June 2021 Accepted: 13 July 2021

Published online: 21 August 2021

\section{References}

1. Nolan JP, Soar J, Cariou A, Cronberg T, Moulaert VR, Deakin CD, Bottiger BW, Friberg H, Sunde K, Sandroni C (2015) European resuscitation council 
and European society of intensive care medicine 2015 guidelines for post-resuscitation care. Intensive Care Med 41(12):2039-2056. https://doi. org/10.1007/s00134-015-4051-3

2. Callaway CW, Donnino MW, Fink EL, Geocadin RG, Golan E, Kern KB, Leary M, Meurer WJ, Peberdy MA, Thompson TM, Zimmerman JL (2015) Part 8: post-cardiac arrest care: 2015 American heart association guidelines update for cardiopulmonary resuscitation and emergency cardiovascular care. Circulation 132(18 Suppl 2):S465-482. https://doi.org/10.1161/CIR. 0000000000000262

3. Rylander C, Friberg H, Larsson EM, Liedholm LJ, Rubertsson S, Cronberg T (2017) Assessment of neurologic prognosis after cardiac arrest. Updated recommendations from the Swedish CPR Council Expert Group. Lakartidningen 114:EIUH

4. Nolan JP, Sandroni C, Bottiger BW, Cariou A, Cronberg T, Friberg H, Genbrugge C, Haywood K, Lilja G, Moulaert VRM, Nikolaou N, Olasveengen TM, Skrifvars MB, Taccone F, Soar J (2021) European resuscitation council and European society of intensive care medicine guidelines 2021: post-resuscitation care. Intensive Care Med. https://doi.org/10.1007/ s00134-021-06368-4

5. Moseby-Knappe M, Westhall E, Backman S, Mattsson-Carlgren N, Dragancea I, Lybeck A, Friberg H, Stammet P, Lilja G, Horn J, Kjaergaard J, Rylander C, Hassager C, Ullen S, Nielsen N, Cronberg T (2020) Performance of a guideline-recommended algorithm for prognostication of poor neurological outcome after cardiac arrest. Intensive Care Med. https://doi.org/10.1007/s00134-020-06080-9

6. Bongiovanni F, Romagnosi F, Barbella G, Di Rocco A, Rossetti AO, Taccone FS, Sandroni C, Oddo M (2020) Standardized EEG analysis to reduce the uncertainty of outcome prognostication after cardiac arrest. Intensive Care Med. https://doi.org/10.1007/s00134-019-05921-6

7. Zhou SE, Maciel CB, Ormseth CH, Beekman R, Gilmore EJ, Greer DM (2019) Distinct predictive values of current neuroprognostic guidelines in post-cardiac arrest patients. Resuscitation. https://doi.org/10.1016/j.resus citation.2019.03.035

8. Elmer J, Torres C, Aufderheide TP, Austin MA, Callaway CW, Golan E, Herren $\mathrm{H}$, Jasti J, Kudenchuk PJ, Scales DC, Stub D, Richardson DK, Zive DM, Resuscitation Outcomes C (2016) Association of early withdrawal of lifesustaining therapy for perceived neurological prognosis with mortality after cardiac arrest. Resuscitation 102:127-135. https://doi.org/10.1016/j. resuscitation.2016.01.016

9. May TL, Ruthazer R, Riker RR, Friberg H, Patel N, Soreide E, Hand R, Stammet P, Dupont A, Hirsch KG, Agarwal S, Wanscher MJ, Dankiewicz J, Nielsen N, Seder DB, Kent DM (2019) Early withdrawal of life support after resuscitation from cardiac arrest is common and may result in additional deaths. Resuscitation 139:308-313. https://doi.org/10.1016/j.resuscitat ion.2019.02.031

10. Ruijter BJ, Tjepkema-Cloostermans MC, Tromp SC, van den Bergh WM, Foudraine NA, Kornips FHM, Drost G, Scholten E, Bosch FH, Beishuizen A, van Putten M, Hofmeijer J (2019) Early electroencephalography for outcome prediction of postanoxic coma: a prospective cohort study. Ann Neurol 86(2):203-214. https://doi.org/10.1002/ana.25518

11. Oh SH, Park KN, Shon YM, Kim YM, Kim HJ, Youn CS, Kim SH, Choi SP, Kim SC (2015) Continuous amplitude-integrated electroencephalographic monitoring is a useful prognostic tool for hypothermia-treated cardiac arrest patients. Circulation 132(12):1094-1103. https://doi.org/10.1161/ CIRCULATIONAHA.115.015754

12. Cloostermans MC, van Meulen FB, Eertman CJ, Hom HW, van Putten MJ (2012) Continuous electroencephalography monitoring for early predic tion of neurological outcome in postanoxic patients after cardiac arrest: a prospective cohort study. Crit Care Med 40(10):2867-2875. https://doi. org/10.1097/CCM.0b013e31825b94f0

13. Rossetti AO, Tovar Quiroga DF, Juan E, Novy J, White RD, Ben-Hamouda N, Britton JW, Oddo M, Rabinstein AA (2017) Electroencephalography predicts poor and good outcomes after cardiac arrest: a two-center study. Crit Care Med 45(7):e674-e682. https://doi.org/10.1097/CCM.0000000000 002337

14. Kim JH, Kim MJ, You JS, Lee HS, Park YS, Park I, Chung SP (2019) Multimodal approach for neurologic prognostication of out-of-hospital cardiac arrest patients undergoing targeted temperature management. Resuscitation 134:33-40. https://doi.org/10.1016/j.resuscitation.2018.11. 007
15. Jang J, Oh SH, Nam Y, Lee K, Choi HS, Jung SL, Ahn KJ, Park KN, Kim BS (2019) Prognostic value of phase information of 2D T2*-weighted gradient echo brain imaging in cardiac arrest survivors: a preliminary study. Resuscitation 140:142-149. https://doi.org/10.1016/j.resuscitation.2019. 05.026

16. Jeon CH, Park JS, Lee JH, Kim H, Kim SC, Park KH, Yi KS, Kim SM, Youn CS, Kim Y-M, Lee BK (2017) Comparison of brain computed tomography and diffusion-weighted magnetic resonance imaging to predict early neurologic outcome before target temperature management comatose cardiac arrest survivors. Resuscitation 118:21-26. https://doi.org/10. 1016/j.resuscitation.2017.06.021

17. Moseby-Knappe M, Pellis T, Dragancea I, Friberg H, Nielsen N, Horn J, Kuiper M, Roncarati A, Siemund R, Unden J, Cronberg T, Investigators TT-t (2017) Head computed tomography for prognostication of poor outcome in comatose patients after cardiac arrest and targeted temperature management. Resuscitation 119:89-94. https://doi.org/10.1016/j.resus citation.2017.06.027

18. Dragancea I, Horn J, Kuiper M, Friberg H, Ullen S, Wetterslev J, Cranshaw J, Hassager C, Nielsen N, Cronberg T, Investigators TTMT (2015) Neurological prognostication after cardiac arrest and targeted temperature management 33 degrees $C$ versus 36 degrees $C$ : results from a randomised controlled clinical trial. Resuscitation 93:164-170. https://doi.org/10. 1016/j.resuscitation.2015.04.013

19. Nielsen N, Wetterslev J, Cronberg T, Erlinge D, Gasche Y, Hassager C, Horn J, Hovdenes J, Kjaergaard J, Kuiper M, Pellis T, Stammet P, Wanscher M, Wise MP, Aneman A, Al-Subaie N, Boesgaard S, Bro-Jeppesen J, Brunetti I, Bugge JF, Hingston CD, Juffermans NP, Koopmans M, Kober L, Langorgen J, Lilja G, Moller JE, Rundgren M, Rylander C, Smid O, Werer C, Winkel P, Friberg $\mathrm{H}$, Investigators TTMT (2013) Targeted temperature management at 33 degrees C versus 36 degrees C after cardiac arrest. N Engl J Med 369(23):2197-2206. https://doi.org/10.1056/NEJMoa1310519

20. Stammet P, Collignon O, Hassager C, Wise MP, Hovdenes J, Aneman A, Horn J, Devaux Y, Erlinge D, Kjaergaard J, Gasche Y, Wanscher M, Cronberg T, Friberg H, Wetterslev J, Pellis T, Kuiper M, Gilson G, Nielsen N, Investigators TT-T (2015) Neuron-specific enolase as a predictor of death or poor neurological outcome after out-of-hospital cardiac arrest and targeted temperature management at 33 degrees $\mathrm{c}$ and 36 degrees C. J Am Coll Cardiol 65(19):2104-2114. https://doi.org/10.1016/j.jacc.2015.03.538

21. Stammet P, Dankiewicz J, Nielsen N, Fays F, Collignon O, Hassager C, Wanscher M, Unden J, Wetterslev J, Pellis T, Aneman A, Hovdenes J, Wise MP, Gilson G, Erlinge D, Horn J, Cronberg T, Kuiper M, Kjaergaard J, Gasche Y, Devaux Y, Friberg $H$, Target Temperature Management after Out-of-Hospital Cardiac Arrest trial (2017) Protein S100 as outcome predictor after out-of-hospital cardiac arrest and targeted temperature management at 33 degrees $C$ and 36 degrees C. Crit Care 21(1):153. https://doi.org/10. 1186/s13054-017-1729-7

22. Moseby-Knappe M, Mattsson N, Nielsen N, Zetterberg H, Blennow K, Dankiewicz J, Dragancea I, Friberg H, Lilja G, Insel PS, Rylander C, Westhall E, Kjaergaard J, Wise MP, Hassager C, Kuiper MA, Stammet P, Wanscher MCJ, Wetterslev J, Erlinge D, Horn J, Pellis T, Cronberg T (2019) Serum neurofilament light chain for prognosis of outcome after cardiac arrest. JAMA Neurol 76(1):64-71. https://doi.org/10.1001/jamaneurol.2018.3223

23. Ebner F, Moseby-Knappe M, Mattsson-Carlgren N, Lilja G, Dragancea I, Unden J, Friberg H, Erlinge D, Kjaergaard J, Hassager C, Wise MP, Kuiper M, Stammet P, Wanscher M, Horn J, Ullen S, Cronberg T, Nielsen N (2020) Serum GFAP and UCH-L1 for the prediction of neurological outcome in comatose cardiac arrest patients. Resuscitation. https://doi.org/10.1016/j. resuscitation.2020.05.016

24. Mattsson N, Zetterberg H, Nielsen N, Blennow K, Dankiewicz J, Friberg H, Lilja G, Insel PS, Rylander C, Stammet P, Aneman A, Hassager C, Kjaergaard J, Kuiper M, Pellis T, Wetterslev J, Wise M, Cronberg T (2017) Serum tau and neurological outcome in cardiac arrest. Ann Neurol 82(5):665-675. https://doi.org/10.1002/ana.25067

25. During J, Annborn M, Cronberg T, Dankiewicz J, Devaux Y, Hassager C, Horn J, Kjaergaard J, Kuiper M, Nikoukhah HR, Stammet P, Unden J, Wanscher MJ, Wise M, Friberg H, Nielsen N (2020) Copeptin as a marker of outcome after cardiac arrest: a sub-study of the TTM trial. Crit Care 24(1):185. https://doi.org/10.1186/s13054-020-02904-8

26. Wihersaari L, Ashton NJ, Reinikainen M, Jakkula P, Pettila V, Hastbacka J, Tiainen M, Loisa P, Friberg H, Cronberg T, Blennow K, Zetterberg H, Skrifvars MB, Comacare Study Group (2020) Neurofilament light 
as an outcome predictor after cardiac arrest: a post hoc analysis of the COMACARE trial. Intensive Care Med. https://doi.org/10.1007/ s00134-020-06218-9

27. Hunziker S, Quinto A, Ramin-Wright M, Becker C, Beck K, Vincent A, Tisljar K, Disanto G, Benkert P, Leppert D, Pargger H, Marsch S, Raoul S, Peters N, Kuhle J (2021) Serum neurofilament measurement improves clinical risk scores for outcome prediction after cardiac arrest: results of a prospective study. Crit Care 25(1):32. https://doi.org/10.1186/s13054-021-03459-y

28. Nielsen N, Winkel P, Cronberg T, Erlinge D, Friberg H, Gasche Y, Hassager C, Horn J, Hovdenes J, Kjaergaard J, Kuiper M, Pellis T, Stammet P, Wanscher M, Wise MP, Aneman A, Wetterslev J (2013) Detailed statistical analysis plan for the target temperature management after out-of-hospital cardiac arrest trial. Trials 14:300. https://doi.org/10.1186/1745-6215-14-300

29. Hviid CVB, Knudsen CS, Parkner T (2020) Reference interval and preanalytical properties of serum neurofilament light chain in Scandinavian adults. Scand J Clin Lab Invest 80(4):291-295. https://doi.org/10.1080/ 00365513.2020 .1730434

30. Bazarian JJ, Biberthaler P, Welch RD, Lewis LM, Barzo P, Bogner-Flatz V Gunnar Brolinson P, Buki A, Chen JY, Christenson RH, Hack D, Huff JS, Johar S, Jordan JD, Leidel BA, Lindner T, Ludington E, Okonkwo DO, Ornato J, Peacock WF, Schmidt K, Tyndall JA, Vossough A, Jagoda AS (2018) Serum GFAP and UCH-L1 for prediction of absence of intracranial injuries on head CT (ALERT-TBI): a multicentre observational study. Lancet Neurol 17(9):782-789. https://doi.org/10.1016/S1474-4422(18)30231-X

31. Mattsson N, Zetterberg H, Janelidze S, Insel PS, Andreasson U, Stomrud E, Palmqvist S, Baker D, Tan Hehir CA, Jeromin A, Hanlon D, Song L, Shaw LM, Trojanowski JQ, Weiner MW, Hansson O, Blennow K, Investigators A (2016) Plasma tau in Alzheimer disease. Neurology 87(17):1827-1835. https://doi.org/10.1212/WNL.0000000000003246

32. Ashton NJ, Suárez-Calvet M, Karikari TK, Lantero-Rodriguez J, Snellman A, Sauer M, Simrén J, Minguillon C, Fauria K, Blennow K, Zetterberg H (2021) Effects of pre-analytical procedures on blood biomarkers for Alzheimer's pathophysiology, glial activation, and neurodegeneration. DADM 13(1):e12168

33. Cronberg T, Horn J, Kuiper MA, Friberg H, Nielsen N (2013) A structured approach to neurologic prognostication in clinical cardiac arrest trials. Scand J Trauma Resusc Emerg Med 21:45. https://doi.org/10.1186/ 1757-7241-21-45

34. Dragancea I, Wise MP, Al-Subaie N, Cranshaw J, Friberg H, Glover G, Pellis T, Rylance R, Walden A, Nielsen N, Cronberg T, Investigators TTMt (2017) Protocol-driven neurological prognostication and withdrawal of life-sustaining therapy after cardiac arrest and targeted temperature management. Resuscitation 117:50-57. https://doi.org/10.1016/j.resus citation.2017.05.014

35. Backman S, Cronberg T, Friberg H, Ullén S, Horn J, Kjaergaard J, Hassager C, Wanscher M, Nielsen N, Westhall E (2018) Highly malignant routine EEG predicts poor prognosis after cardiac arrest in the target temperature management trial. Resuscitation 131:24-28

36. Westhall E, Rossetti AO, van Rootselaar AF, Wesenberg Kjaer T, Horn J, Ullen S, Friberg H, Nielsen N, Rosen I, Aneman A, Erlinge D, Gasche Y, Hassager C, Hovdenes J, Kjaergaard J, Kuiper M, Pellis T, Stammet P, Wanscher M, Wetterslev J, Wise MP, Cronberg T, Investigators TTMt (2016) Standardized EEG interpretation accurately predicts prognosis after cardiac arrest. Neurology 86(16):1482-1490. https://doi.org/10.1212/WNL.0000000000 002462

37. Lybeck A, Friberg H, Aneman A, Hassager C, Horn J, Kjaergaard J, Kuiper M, Nielsen N, Ullen S, Wise MP, Westhall E, Cronberg T, Investigators TTMt (2017) Prognostic significance of clinical seizures after cardiac arrest and target temperature management. Resuscitation 114:146-151. https://doi. org/10.1016/j.resuscitation.2017.01.017

38. Simundic AM (2009) Measures of diagnostic accuracy: basic definitions. EJIFCC 19(4):203-211

39. Cohen JF, Korevaar DA, Altman DG, Bruns DE, Gatsonis CA, Hooft L, Irwig L, Levine D, Reitsma JB, de Vet HC, Bossuyt PM (2016) STARD 2015 guidelines for reporting diagnostic accuracy studies: explanation and elaboration. BMJ Open 6(11):e012799. https://doi.org/10.1136/bmjop en-2016-012799

40. RCT (2017) R; a language and environment for statistical computing. https://www.R-project.org/. Accessed 21 July 2021

41. Lybeck A, Cronberg T, Aneman A, Hassager C, Horn J, Hovdenes J, Kjaergaard J, Kuiper M, Wanscher M, Stammet P, Wise MP, Nielsen N, Ullen $\mathrm{S}$, Friberg H, Investigators TTMt (2018) Time to awakening after cardiac arrest and the association with target temperature management. Resuscitation 126:166-171. https://doi.org/10.1016/j.resuscitation.2018.01.027

42. Streitberger KJ, Leithner C, Wattenberg M, Tonner PH, Hasslacher J, Joannidis M, Pellis T, Di Luca E, Fodisch M, Krannich A, Ploner CJ, Storm C (2017) Neuron-specific enolase predicts poor outcome after cardiac arrest and targeted temperature management: a multicenter study on 1,053 patients. Crit Care Med 45(7):1145-1151. https://doi.org/10.1097/ CCM.0000000000002335

43. Hol EM, Pekny M (2015) Glial fibrillary acidic protein (GFAP) and the astrocyte intermediate filament system in diseases of the central nervous system. Curr Opin Cell Biol 32:121-130. https://doi.org/10.1016/j.ceb. 2015.02.004

44. Pekny M, Nilsson M (2005) Astrocyte activation and reactive gliosis. Glia 50(4):427-434. https://doi.org/10.1002/glia.20207

45. Al. Ume (2020) The human protein atlas. KTH, UU, SciLifeLab, Sweden. http://www.proteinatlas.org/. Accessed 31 May 2021

46. Khalil M, Teunissen CE, Otto M, PiehI F, Sormani MP, Gattringer T, Barro C, Kappos L, Comabella M, Fazekas F, Petzold A, Blennow K, Zetterberg H, Kuhle J (2018) Neurofilaments as biomarkers in neurological disorders. Nat Rev Neurol 14(10):577-589. https://doi.org/10.1038/ s41582-018-0058-Z

47. Huebschmann NA, Luoto TM, Karr JE, Berghem K, Blennow K, Zetterberg H, Ashton NJ, Simren J, Posti JP, Gill JM, Iverson GL (2020) Comparing glial fibrillary acidic protein (GFAP) in serum and plasma following mild traumatic brain injury in older adults. Front Neurol 11:1054. https://doi. org/10.3389/fneur.2020.01054

48. Anckarsater R, Anckarsater H, Bromander S, Blennow K, Wass C, Zetterberg H (2014) Non-neurological surgery and cerebrospinal fluid biomarkers for neuronal and astroglial integrity. J Neural Transm (Vienna) 121(6):649-653. https://doi.org/10.1007/s00702-013-1156-0

49. Danielson M, Wiklund A, Granath F, Blennow K, Mkrtchian S, Nellgard B, Oras J, Fagerlund MJ, Granstrom A, Schening A, Rasmussen LS, Harris HE, Zetterberg H, Ricksten SE, Eriksson LI (2021) Association between cerebrospinal fluid biomarkers of neuronal injury or amyloidosis and cognitive decline after major surgery. Br J Anaesth 126(2):467-476. https:// doi.org/10.1016/j.bja.2020.09.043

50. Moseby-Knappe M, Cronberg T (2020) Blood biomarkers of brain injury after cardiac arrest - a dynamic field. Resuscitation. https://doi.org/10. 1016/j.resuscitation.2020.09.004

51. Anderson TN, Hwang J, Munar M, Papa L, Hinson HE, Vaughan A, Rowell SE (2020) Blood-based biomarkers for prediction of intracranial hemorrhage and outcome in patients with moderate or severe traumatic brain injury. J Trauma Acute Care Surg 89(1):80-86. https://doi.org/10.1097/TA. 0000000000002706 